\title{
POLÍTICAS PÚBLICAS PARA EDUCAÇÃO DE PESSOAS SURDAS: conquistas, paradoxos e impasses
}

\section{PUBLIC POLICIES FOR THE EDUCATION OF DEAF PEOPLE: achievements, paradoxes and impasses}

\author{
Bruno Rege Lopes \\ Mônica Maria dos Santos ${ }^{2}$
}

\begin{abstract}
Resumo
Políticas públicas são resultado de lutas sociais que garantam o acesso de grupos minoritários a direitos previstos na legislação. No Brasil, a instituição de políticas públicas educacionais tem promovido avanços significativos no acesso de pessoas surdas à escola e ao mercado de trabalho. Essa pesquisa descreve como esses avanços foram consolidados ao longo da história e o impacto na vida dos sujeitos surdos. Para tal, elegemos a revisão bibliográfica e o relato de experiência, mediante observação e estudo de caso, que permitiu perceber a efetividade das políticas públicas voltadas à educação de surdos, principalmente, sobre a acessibilidade de Educação Bilíngue.
\end{abstract}

Palavras-chave: Políticas públicas. Educação inclusiva. Pessoas surdas.

\begin{abstract}
Public policies are the results of social fights that guarantee the access of the minority groups to rights provides for in the legislation. In Brazil, the institution of educational public policies has promoted significant advances at the access of deaf people to the schools and the labor market. This research describes how these advances have been consolidated over history and how they impacted at the life of these people. To this end, we elected the literature review and the report of the experience, from the observation of the case study, that allowed to perceive the effectiveness of public policies aimed at the education of the deaf, mainly on the accessibility of Bilingual Education.
\end{abstract}

Keywords: Public policies. Inclusive Education. Deaf people.

\section{Introdução}

As políticas públicas surgem para solucionar inquietações populares. São formadas

1Graduado em Letras - Língua Portuguesa e Literaturas de Língua Portuguesa pela Universidade Federal de Mato Grosso- UFMT. E-mail: regebrl@gmail.com.

2 Doutoranda em Estudos Literários no Programa de Pós-Graduação em Estudos da Linguagem - PPGEL da Universidade Federal de Mato Grosso- UFMT. Mestre em Letras pela Universidade Federal de RondôniaUNIR.E-mail: monicamagnificamv@gmail.com. 


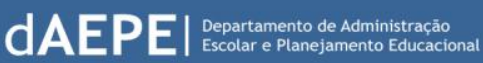

por um conjunto de programas, ações e decisões tomadas pelo governo, não necessariamente a somatória de todo conjunto, mas sob a consequência deles. Seguem em linha tênue com o planejamento do setor público, e a qualidade deste planejamento e da efetivação das ações geradas a partir dele refletem diretamente na sociedade (SOUZA, 2006).

É comum que elas estejam ligadas a duas vertentes, uma de viés político que estará voltada a interesses de grupos específicos, e outra, que segue um viés administrativo que, por sua vez, é o resultado dessas políticas para a sociedade. Não diferente, podemos dizer que as políticas públicas da educação são as responsáveis pelo desenvolvimento do país, uma vez que são elas quem garantem alfabetização, especialização e profissionalização.

Uma das garantias fundamentais ao cidadão, segundo a Declaração Universal de Direitos Humanos, é a de acesso à educação. Amparada nesta égide, diversas ações e decisões foram postas e a acessibilidade à educação contemplou as pessoas com deficiência. A Educação Especial é resultante de diversas decisões sobre educação igualitária para todas as pessoas, a partir dela, surgiu também a proposta de Educação Inclusiva, que são ações da educação especial em escolas de ensino regular. A proposta de Educação Inclusiva legitima o ingresso de alunos com deficiência em escolas de ensino regular, neste contexto também se inserem os alunos surdos. E é sobre a educação destas pessoas que trataremos nesta pesquisa.

Dentre as possibilidades metodológicas de ensino para pessoas surdas na Educação Inclusiva, algumas instituições elegem o ensino de Língua Portuguesa (LP), ministrado por professor ouvinte e interpretado em Língua Brasileira de Sinais (LIBRAS) por um profissional intérprete, o que gera uma expectativa nas instituições de ensino, de que os alunos surdos cheguem à escola com uma linguagem definida e que corresponda ao seu impedimento sensorial auditivo, e, simultaneamente tenham a mesma compreensão dos ouvintes sobre a LP. No entanto, esta expectativa, por vezes, é frustrada por esses alunos não terem uma linguagem definida, sob a hipótese de estarem em um ambiente linguístico que não favorece a aquisição natural, de uma Língua de Sinais (LS) ou Libras.

Diante essa problemática, sob um olhar mais voltado aos estudos da língua é o presente artigo parte de inquietações acerca de como se efetiva o ensino de Língua Portuguesa para alunos surdos sob uma perspectiva das Políticas Públicas de Educação Inclusiva. Essa questão se justifica, pois, as Políticas Públicas de Educação Especial e consequentemente de 


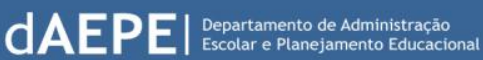

Educação Inclusiva, sugerem o ensino de LP como segunda língua para alunos surdos, que muitas vezes, não têm uma primeira língua definida. Doravante, trataremos os termos primeira língua e segunda língua como L1 e L2, respectivamente.

Diante disto, elegemos o estudo de revisão e relato de experiência, a partir de observação e estudo de caso, como metodologias para a investigação científica. Foram realizadas revisões de literaturas como: a história da educação de pessoas surdas sob um olhar cultural; as Políticas Públicas de Educação de surdos sob uma perspectiva da Educação Inclusiva e a Educação Bilíngue; o processo de luto simbólico de famílias de pessoas ouvintes que tiveram filhos surdos. Além do relato e da observação de duas famílias de pessoas ouvintes e falantes de LP, que tiveram filhos diagnosticados com surdez profunda logo nos primeiros anos de vida.

As famílias são moradoras do município de Barra do Garças - MT. A observação tinha como objetivo a investigação de como as Políticas Públicas de Educação Inclusiva contribuíram para o aprendizado de LP dos filhos surdos, e como as famílias participaram da educação destes, diante dos processos psicológicos gerados por um provável desconhecimento das peculiaridades linguísticas do filho surdo.

\section{Políticas de Educação Especial e Educação Inclusiva}

Nas duas últimas décadas é notória a percepção do Estado sobre as políticas públicas de inclusão de pessoas com deficiência nas escolas de ensino regular, todavia, para que houvesse qualquer sensibilidade foi necessário trilhar um percurso de lutas por direitos. Sabese que as políticas públicas, enquanto propostas de solução de problemas sociais, são resultado de inquietações de determinados grupos de pessoas que compartilham de singularidades. Não diferente, as políticas públicas de educação especial resultam de um longo processo que acompanha os pensamentos de determinadas épocas na história da humanidade.

Em um contexto mais amplo, pessoas com deficiência, foram estigmatizadas de diversas formas desde a antiguidade (355 a.C.), coadunando com pensamentos de filósofos com Aristóteles. Na idade média (século $\mathrm{V}$ ao século XV), o pensamento teocêntrico, por vezes, interpretado de maneira errônea, concebia essas pessoas como resultado de um pecado 


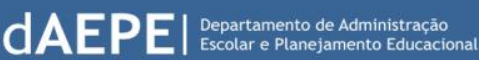

familiar. A partir da idade moderna (século XV ao século XVIII), com a emergência dos estudos científicos, novos olhares foram lançados sobre pessoas com deficiência, ainda de maneira muito dispersa, e iniciadas pesquisas sobre as deficiências. Diante dessa evolução, as propostas de intervenção foram alçadas, inicialmente (século XIX) institucionalizando o isolamento destas pessoas em manicômios, orfanatos e prisões (ZAVAREZE, 2009).

Esse período sombrio perdurou séculos e, a percepção torpe da sociedade sobre as pessoas com deficiência mental, sensorial ou motora era acompanhada de uma total incompreensão sobre as capacidades intelectuais destas. Consequentemente, o impedimento de acesso à educação seguia em linha tênue com o isolamento de outras áreas (citamos neste caso, o apoio clínico). Somente no século $\mathrm{XX}$, as pessoas com deficiência passaram a ser vistas com mais humanidade, neste sentido, surgiram instituições que se propuseram à educálas (ZAVAREZE, 2009).

Nesta seara, discussões sobre Educação Especial passaram a ser colocadas em questão em congressos internacionais. As discussões durante a segunda metade do século XX eram mais sensíveis às pessoas com deficiência, e isso gerou como resultado no Brasil, a assinatura de acordos internacionais, a exemplo da Declaração Mundial de Educação para todos, que foi confeccionada durante um congresso em Jomtien, na Tailândia, em 1990. A partir do fortalecimento de discussões sobre a égide do compromisso do Estado em ofertar educação de maneira igualitária a todas as pessoas, os grupos organizados fortaleceram a luta por direitos e garantias educacionais a pessoas com deficiência, em um contexto nacional. Em 1996, foi assinada a Declaração de Salamanca, que resulta de uma reunião das Nações Unidas onde foram discutidas questões sobre princípios, políticas e práticas na área das necessidades educacionais especiais.

A partir deste momento, as pessoas com deficiência deixam de ser marginalizadas educacionalmente, conincidindo no Brasil, como o início de formulações de práticas de Educação Especial. Para descrevê-la, resgatamos um trecho da Lei n ${ }^{\circ} 9.394$ de 20 de dezembro de 1996, também conhecida como Lei de Diretrizes e Bases da Educação Nacional (LDBEN):

Art. 58. Entende-se por educação especial, para os efeitos desta Lei, a modalidade de educação escolar oferecida preferencialmente na rede regular 


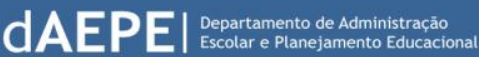

de ensino, para educandos com deficiência, transtornos globais do desenvolvimento e altas habilidades ou superdotação. (BRASIL, 1996, p. 24)

Esta modalidade de educação atende um público-alvo específico. Nesse sentido, também se enquadra o atendimento às pessoas com impedimento sensorial auditivo. No entanto, a conquista do amparo legal não garantiu a qualidade de acesso dessas pessoas à educação, pois o processo evoluiu de maneira descompassada, os textos legais não acompanhavam, muito menos, abrangiam as necessidades das pessoas com deficiências, se limitando ao atendimento especial.

Em 1973, é criado no MEC, o Centro Nacional de Educação Especial CENESP, responsável pela gerência da educação especial no Brasil, que, sob a égide integracionista, impulsionou ações educacionais voltadas às pessoas com deficiência e às pessoas com superdotação; ainda configuradas por campanhas assistenciais e ações isoladas do Estado. Nesse período, não se efetiva uma política pública de acesso universal à educação, permanecendo a concepção de 'políticas especiais' para tratar da temática da educação de alunos com deficiência e, no que se refere aos alunos com superdotação, apesar do acesso ao ensino regular, não é organizado um atendimento especializado que considere as singularidades de aprendizagem desses alunos. (BRASIL, 2008, p. 09)

Diante todo exposto, consideramos que a educação de pessoas com deficiência, até a década de 1990 era de certo modo negligenciada, todavia, houve neste período uma virada, cultural, política e social que culminou ações conjuntas de grupos de trabalho que galgaram a instauração destas políticas públicas. Cabe ressaltar que existiam garantias, não apenas no campo educacional, mas também nos campos da saúde e na assistência social às pessoas com deficiência, em consonância com os ganhos educacionais (THOMA; KLEIN, 2010).

O fortalecimento das políticas públicas, ao mesmo tempo em que nascem de inquietações e problemas de grupos sociais, resultam de certo modo, no retrato que a sociedade tem sobre determinados assuntos, pois, efetivamente, os textos legais acompanham a evolução intelectual e social da humanidade, e, não diferente, ocorreu nas políticas públicas voltadas às pessoas com deficiência. Atualmente, com uma maior racionalidade fortalecida pela Declaração Universal dos Direitos Humanos, as pessoas com deficiência foram vistas em paridade com aquelas que não têm algum tipo de impedimento sensorial, motor ou intelectual. 


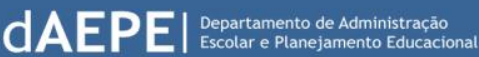

Percebe-se que pelo status de verdade, as legislações denotam qual o retrato que a sociedade terá sobre determinada questão. No caso das políticas públicas de educação especial/inclusiva, a maneira que a legislação é posta, influencia diretamente no pensamento social sobre as pessoas com deficiência. Deste modo, tais políticas demandam também elementos de humanidade e sensibilidade de quem as materializa, uma vez que por buscar atender as necessidades de todos, torna-se genérica, fortalecendo o preconceito sobre as formas de impedimentos sensoriais, mentais ou de mobilidade.

A mola precursora da Educação Especial é a oferta de igualdade de oportunidades a todos, independentemente de suas necessidades educacionais. Essa questão é o que fortaleceu a adaptação do Atendimento Educacional Especializado nas escolas de ensino regular, a chamada Educação Inclusiva. Evidente um intuito de igualdade de oportunidades, e que existe uma necessidade intrínseca de que os alunos com necessidades educacionais especiais e os alunos regulares estejam no mesmo ambiente. Este discurso tem fortes vínculos e se fundamenta na teoria de interação social.

A Educação Inclusiva, ao contrário do que se pensa, é um braço da Educação Especial, com o objetivo de fornecer situação de igualdade entre os alunos público-alvo dessa educação e os demais alunos, o que se calça como diferença é que a educação inclusiva aproxima o aluno com necessidades educacionais especiais do aluno regular ${ }^{3}$. Do mesmo modo, as práticas de educação inclusiva são norteadas por textos que têm força de legislação e orientam as equipes multiprofissionais sobre as metodologias a serem aplicadas.

A educação de pessoas surdas, na perspectiva da Educação Inclusiva, ocorre a partir do respeito às singularidades linguísticas das pessoas com impedimento sensorial auditivo, sejam elas, surdas ou deficientes auditivas. Os princípios fundamentais para a educação de surdos está calçado além dos textos supramencionados que contemplam a Educação Especial de modo geral, na Lei no 10.436 de 24 de abril de 2002 que legitima a Língua Brasileira de Sinais (Libras) como meio de comunicação oficial das pessoas surdas, também do Decreto $\mathrm{n}^{\circ}$ 5.626 de 22 de dezembro de 2005, que por sua vez estabelece as diretrizes para a educação de

3usamos o termo neste contexto, para referenciar o aluno que, segundo a idealização social ouvintista, não tem nenhum impedimento auditivo ou fonológico, que seja falante da Língua Portuguesa e filho de pai e mãe ouvintes e falantes da mesma língua. $\mathrm{O}$ aluno que tem adquiriu a LP na modalidade oral como sua L1. 


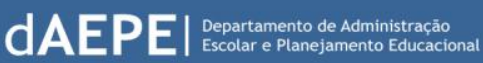

pessoas surdas, e ainda fornece demais garantias no contexto social, educacional, saúde e assistencial.

Outras várias discussões sobre educação inclusiva foram feitas, resultando em textos como o da Política Nacional de Educação Especial na perspectiva da Educação Inclusiva, que em resumo, tem força de uma legislação, que relaciona essa educação como peça fundamental para o respeito aos direitos humanos. O texto garante a "Transversalidade da educação especial desde a educação infantil até a educação superior” (BRASIL, 2008, p.14). O documento define alguns termos, em especial, direciona sobre o Atendimento Educacional Especializado, que em suma, são 45 itens de práticas metodológicas de recepção e acompanhamento do aluno com necessidades educacionais especiais.

Citamos como exemplo, a indicação de que a metodologia aplicada para fundamentar a alfabetização e ensino de Língua Portuguesa às pessoas surdas, que orienta que o ensino de Língua Portuguesa, seja ensinado na modalidade escrita como L2. Ou seja, considera-se que a Libras seja a primeira língua da criança surda.

Não podemos deixar de considerar que as legislações em vigor são precursoras no contexto nacional e, embora, até o momento, se discutam questões a serem modificadas. No entanto, foram esses textos que legitimaram diversas ações e serviram como pilares para a adaptação de metodologias, por exemplo. Não obstante, foram os textos supramencionados que serviram e servem até hoje de base para discussões sobre educação de pessoas surdas, tendo sido confeccionadas por grupos de trabalho que atuavam na educação de surdos e, principalmente, tinham um olhar sensível às peculiaridades linguísticas destas pessoas (BRASIL, 2004).

\section{O sujeito surdo}

Entendemos que como todo e qualquer sujeito, a pessoa surda carrega consigo singularidades que as difere de uns e as assemelham a outros, compartilhando a condição clínica de surdez,. No entanto, a percepção desta condição, por vezes, os diferencia para além, principalmente, sob um olhar sociocultural da surdez. O saber médico diferencia os termos pelo grau de impedimento, medido em decibéis, considerando a perda auditiva de até quarenta decibéis como surdez leve, e, entre quarenta e setenta decibéis, como surdez moderada. As 


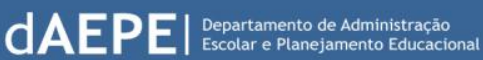

pessoas que se enquadram neste quesito clínico são chamadas de "deficientes auditivos". Já aqueles que apresentam perda auditiva entre setenta e noventa decibéis, definida como surdez severa e, os que apresentam perda auditiva superior a noventa decibéis, chamada de surdez profunda, são considerados nos termos clínicos como surdos (BRASIL, 2006).

Para Silva (2007), as definições acima mencionadas são chamadas de concepções clínico terapêuticas. Em contraponto, a visão socioantropológica entende como "surdo" toda pessoa que não escuta, independente do grau de perda auditiva, observando o sujeito e não o impedimento sensorial. Essa percepção parte da história das pessoas surdas que durante toda a história foram estigmatizadas e marginalizadas, pois a principal problemática que se tem é a diferença de comunicação entre pessoa surda e ouvintes.

Com isto, por vezes, os surdos foram considerados pessoas incapazes de deter conhecimentos ou de aprendizado. Porém, é importante recordar que nesta seara, entre uma mudança e outra de concepção sobre a surdez, inclusive no tocante a políticas educacionais, que mais sofriam eram os próprios surdos, que por séculos foram submetidos a práticas torturantes que elucidavam a obrigatoriedade de oralizar.

A acepção de Cultura Surda está em linha tênue com a antropologia, neste sentido, a história dos surdos foi quem favoreceu de maneira impar o surgimento desta cultura, que se manifesta principalmente na comunicação, pelo uso de Língua de Sinais.

É notório que, para a construção de uma cultura, é necessário que haja interação entre pessoas que compartilham de hábitos e princípios semelhantes. Neste sentido, a Cultura Surda, representada por grupos da Comunidade Surda, são a representação destes hábitos e princípios. É sobre essa diversidade cultural que Wrigley (1996) afirma que a surdez é um país sem lugar próprio. Além disto Perlin (1998) considera alguns aspectos de identificação aos sujeitos surdos, a chamada de Identidade Surda. A autora sugere cinco tipos distintos de identidade: a Flutuante, que se manifesta de acordo com o mundo ouvinte; a Inconformada, que se sente subalterna aos ouvintes; a de Transição, quando o surdo passa por conflitos culturais; a Hibrida, de surdos que nasceram ouvintes, e por último, a Identidade Surda que é aquele que se aceita e aceita a luta política, social e cultural da Comunidade Surda, em favor do sujeito surdo. Em uma percepção de política educacional e voltada à aquisição de linguagem, a interação com a cultura surda poderá oferecer à criança surda um ambiente 


\section{dAEPE|}

linguístico que favoreça a aquisição de uma LS.

Sobre o assunto, Morato (2015, p. 37) considera que "é por meio da internalização de experiências culturais que a criança incorpora formas linguístico-cognitivas". A importância da aquisição de uma LS pela criança surda, na performance educacional que dessa criança, está além dos aspectos culturais e de interação social, uma vez que sob a perspectiva de educação inclusiva, o processo de ensino de diversas disciplinas, inclusive a LP, será traduzido por um intérprete de LS.

\section{O que é legal e o que é real na atual política educacional}

O ganho nas políticas públicas de Educação de Surdo ao longo das últimas décadas é inegável, grupos organizados se mobilizaram e hoje existem muitas garantias às pessoas surdas. Neste sentido, citamos a garantia da presença de profissionais intérpretes de Libras em salas de aula; a formação docente para pessoas surdas; o Atendimento Educacional Especial (AEE), disposto em contra turno; a obrigatoriedade da disciplina de Libras nos cursos de Licenciatura e Fonoaudiologia; além os diversos cursos de Libras tanto para pessoas surdas quanto para ouvintes. Mas de certo modo, uma das maiores garantias dispostas nos textos legais é a do ensino de LP como L2, demonstrando um olhar mais sensível das políticas públicas sobre o aluno surdo.

A percepção de que o ensino de LP deve ser ministrado como L2 segue em linha tênue com estudos linguísticos e cognitivos das pessoas surdas. Uma vez que as pessoas que apresentam impedimento sensorial auditivo, comumente, tendem a ter percepções visuais mais aguçadas, o que favorece a aquisição de uma linguagem que ocupe o canal espaço manual.

Essa tendência acontece em razão de uma compensação neurológica a perda auditiva, também chamada de plasticidade cerebral, que é a adaptação do sistema nervoso a alguma peculiaridade cerebral (LENT, 2010). Entendemos, então, que os surdos tendem linguisticamente a ter uma competência linguística voltada às Línguas de Sinais, mas essa competência só irá progredir para o status de performance linguística, se a criança surda for inserida em um ambiente linguístico compatível com seu impedimento sensorial.

Diante do notório fato de que pessoas surdas têm melhores percepções visuais, se 


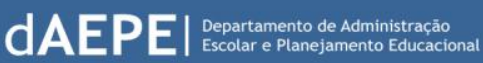

comparadas a pessoas ouvintes, corrobora-se a afirmativa de que o mundo do surdo é visual. Mas para além da acuidade visual, a plasticidade cerebral é que permite às relações sinápticas firmarem-se para o armazenamento de memórias e aprendizado. Dentre os modos de aprendizado está a aquisição de uma linguagem, que ocorrerá de maneira espontânea se a criança for inserida em um ambiente que permita input linguístico compatível com seu impedimento sensorial. Cabe ressaltar que a teoria gerativa firmada nos estudos de Chomsky (1971) concebe como um fenômeno mental inato, a aquisição da linguagem, e, mesmo com impedimento sonoro, as crianças surdas corresponderão a um input exclusivamente visual.

Neste caso, é intrínseco que o fornecimento de um ambiente linguístico favorável a aquisição de LS é uma decisão da família, principalmente dos pais, pela responsabilidade legal que exercem sobre os filhos. No entanto, nem sempre os pais têm compreensão das peculiaridades linguísticas do filho, pois, por vezes, estes pais são ouvintes, e ter um filho surdo, provavelmente, não era algo que estes imaginavam.

Essa peculiaridade, de pais ouvintes com filhos surdos, é palco de diversas discussões, pois entende-se que estes formam aproximadamente $95 \%$ das pessoas que tem filhos surdos. O que sugere uma provável incompreensão sobre o impedimento sonoro da criança, além de um provável luto psicológico por ter um filho diagnosticado com surdez (LOPES; SANTOS, 2020).

A falta de orientação ou a orientação unilateral, que aborda unicamente possibilidades de intervenções clínicas à surdez, acentua a problemática de uma provável ausência de linguagem ou uma linguagem indefinida na criança surda, peculiaridade que futuramente é transferida aos sistemas de ensino, e é pra isso que as políticas Educacionais precisam também atentar. Essa questão, por vezes, é a causa de impasses na Educação Inclusiva, que elege pelas políticas públicas convencionais, metodologias de educação, como o ensino de disciplinas interpretadas em Libras, com a expectativa de que esta seja a língua de uso da criança surda.

Esse impasse, em vários momentos, é acentuado por não haver alternativas secundárias, salvo o Auxiliar de Ensino Especial-AAE, que em um mundo ideal, compensaria essa ausência da Libras. Cabe ressaltar ainda que este atendimento é ofertado apenas, a partir do consentimento da família. No entanto, na prática observa-se a demora na contratação de 


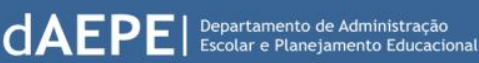

profissionais intérpretes de Libras, por questões burocráticas da administração pública, também a ausência de sala de recursos em algumas escolas, principalmente nas de ensino público, distanciando as políticas públicas educacionais do público em tela.

Percebemos com isso que as particularidades do processo de ensino de LP para alunos surdos, não se situam somente no aluno, pelo contrário, existem pontos a serem considerados, como o comprometimento e sensibilidade dos docentes com a educação do aluno surdo, lacunas na formação continuada, falta de assistência dos Sistemas. Por vezes, a inclusão de um aluno com necessidades educacionais especiais em sala de aula de ensino regular é vista como um desafio, e não como uma diferença dentro da diversidade cultural. A influência da família no incentivo do contato da criança surda com a LS, haja vista que como mencionado, a família, como primeiro grupo social com o qual a criança interage, terá uma responsabilidade intrínseca na construção linguística desse aluno.

O fato de haver garantia legal do intérprete em sala de aula, não resolve a comunicação entre aluno e professor, salvo se este for sensível à peculiaridade linguística do aluno surdo. E isso se estende a outros serviços, que não só os educacionais que não correspondem diretamente às necessidades do cidadão surdo, que como qualquer outra pessoa, precisa de comunicação efetiva em todos os setores da vida, a exemplo do acesso dos recursos de saúde e segurança.

Além disto, a política de Educação Inclusiva, no que diz respeito ao ensino de LP, permanece com uma metodologia incompatível com a demanda do aluno surdo, que diferente do aluno ouvinte, aprende a Língua Portuguesa como L2, uma língua diferente da sua língua de uso cotidiano, em aspectos gramaticais e de canais sensoriais. Isso gera um paradoxo entre o que é legal e o que é real, pois enquanto os textos legais congregam o ensino de LP como L2, a metodologia amparada na política pública de inclusão aplicada em sala de aula não abrange o ensino bilíngue.

Sobre a modalidade ensino bilíngue, cabe ressaltar que ela permite que o ensino de LP e de Libras ocorra em momentos distintos, propiciando que cada língua assuma seu lugar. No que diz respeito aos estudos de linguagem, as crianças são educadas na metodologia bilíngue com o foco na aquisição da Libras como L1 e da LP como L2. Existem instituições de ensino que contemplam a educação bilíngue, até mesmo em escolas com metodologia inclusiva, onde 


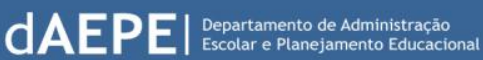

o conteúdo e o material didático são adaptados à realidade dos surdos e o ensino é realizado por meio da Libras. Esta modalidade é advogada por muitos grupos de pessoas surdas e pesquisadores da área como ideal a educação de surdos, no entanto, ainda não é uma realidade de que contemple todo o território nacional.

\section{Algumas considerações}

As políticas públicas para a educação de pessoas surdas a partir da Educação Especial, em uma perspectiva inclusiva permitiram acessibilidade de surdos e deficientes auditivos a alfabetização e para além disto, essas políticas tiram as pessoas surdas das prisões/esconderijos familiares, mesmo que ainda de forma muito deficitária proporcionam o direito ao espaço social do sujeito surdo. Deste modo, são notórios os feitos destas políticas, mas cabe ressaltar que todas elas partiram de inquietações e movimentos de grupos de trabalhos, sensíveis a estas pessoas.

Diante da observação das legislações que norteiam a educação de pessoas surdas, em uma perspectiva da Educação Inclusiva, percebemos que houve um grande avanço e que a educação de surdos respeita as singularidades linguísticas destas pessoas. No entanto, existe a necessidade de que as ações em favor da educação de surdos sejam positivas, com um olhar mais sensível à vida do aluno antes de seu ingresso na escola, uma vez que como abordado anteriormente, muitos destes são matriculados na rede regular sem ter uma linguagem definida, o que pode comprometer o desempenho educacional e a interação no ambiente escolar.

É evidente que a política para a educação de pessoas surdas deve caminhar para uma proposta bilíngue, que permita que disciplinas como matemática, sejam ministradas em Libras, com tradução simultânea para os alunos. Para além disto, percebemos que grande parte dos impasses na materialização de politicas públicas educacionais encontra-se em peculiaridades que ocorrem fora do ambiente escolar. Podemos citar a falta de orientação às famílias após o diagnóstico de surdez do filho, a ausência de equipes multiprofissionais com fluência em LS, dentre outros fatores.

Com isso, congregamos a assertividade de políticas públicas educacionais em parceria 


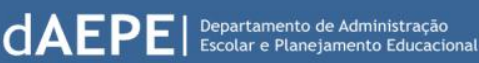

com aquelas voltadas à saúde e assistência social aos surdos, no sentido de que estas estejam em harmonia, haja vista que as políticas públicas caminham para solucionar problemas sociais. Neste sentido, acreditamos que se houver efetivamente ações de equipes multiprofissionais desde o nascimento da criança surda ou descoberta da perda auditiva, as possibilidades de sucesso educacional aumentarão exponencialmente.

A prova de que as atuais políticas públicas são favoráveis à educação de pessoas surdas está na observação feita durante pesquisa de campo sobre o aprendizado de Língua Portuguesa como L2 por alunos surdos, filhos de pais ouvintes, residentes no município de Barra do Garças - Mato Grosso. Realizamos a observação de duas famílias que se enquadram nos aspectos supramencionados, que trataremos como família A e família B.

No caso da família $\mathrm{A}$, notamos que o luto dos pais, associado à dificuldade de comunicação com o filho e as políticas públicas do período (cabe a ressalva de que este filho iniciou os estudos antes das leis que amparavam o ensino de LP como L2), trouxeram um atraso de aproximadamente três anos, sob a expectativa de desenvolvimento escolar (relação idade e ano escolar). E sobre o aspecto do aprendizado da LP, o ambiente linguístico desfavorável fez com que este filho tivesse acesso tardio (em relação ao ingresso escolar) à LIBRAS, o que, consequentemente, gerou um atraso no aprendizado da LP. No entanto, ao que se percebe, o atraso no aprendizado de LP não o impediu de concluir um curso superior, que dado o panorama e possíveis traumas gerados pelas contradições metodológicas na política de Educação Inclusiva para surdos, torna-se um dado surpreendente.

No caso da família $B$, percebemos que fatores que incluem a orientação familiar, políticas públicas e condição social, foram determinantes para que o aluno correspondesse positivamente às expectativas de desenvolvimento escolar. O luto da mãe interferiu apenas no fator de interação social do filho, visto uma provável superproteção a que foi submetido.

Quanto ao aspecto linguístico, no que diz respeito ao aprendizado de LP como L2, o filho surdo, ao que se percebe, apresenta boa compreensão gramatical e faz uso correto das estruturas sintáticas, o que acreditamos ser resultado das políticas públicas educacionais existentes à época de sua alfabetização, e ao acompanhamento educacional prestado pela mãe. Cabe ressaltar que este aluno ingressou em escolas que contemplavam a educação inclusiva desde a alfabetização, contudo, o uso correto da norma não garante que este filho compreenda 


\section{dAEPE|}

e interprete estruturas mais complexas da LP.

No entanto, em um aspecto social, percebemos que os dois filhos surdos das famílias investigadas têm ótima relação com os pais e conseguem interagir de uma maneira muito surpreendente. Congregamos este fato ao contato dos filhos com a língua, e além disto, com usuários desta língua, a Comunidade Surda.

[...] A influência da surdez sobre o indivíduo mostra características bastante particulares desde seu desenvolvimento físico e mental até seu comportamento como ser social. Neste aspecto, destaca-se a linguagem como fator de vital importância para o desenvolvimento de processos mentais, personalidade e integração social do surdo. (FERNANDES, 2000, p. 49)

Todavia, existe a compreensão de que não basta que as políticas públicas favoreçam a inclusão institucional, se não houver inclusão social. Em uma breve analogia, consideramos que a acessibilidade de pessoas com impedimento motor está em grande parte na adequação estrutural de ambientes, que possibilitem a mobilidade destas pessoas. Em contraponto, a acessibilidade que se almeja para as pessoas surdas vai além de salas de aula inclusivas, estando concentrada também na reestruturação social, para que haja a possibilidade da sociedade ter conhecimento sobre a história e cultura surda, sobretudo, que tenham acesso ao aprendizado de Libras, uma vez que o que se espera, é que em todos os ambientes tenham pessoas fluentes na língua.

O que se reflete aqui é a urgência de reestruturação de políticas públicas educacionais que priorizem a formação continuada de professores, rumo a uma educação bilíngue, que atenda as expectativas linguísticas das crianças surdas, no entendimento de que a quebra da barreira de comunicação entre surdos e ouvintes é o elemento primordial para a efetivação da real inclusão social.

\section{Referências}

BRASIL. Decreto n. ${ }^{\circ}$ 5.626, de 22 de dezembro de 2005. Regulamenta a Lei $\mathrm{n}^{\circ} 10.436$, de 24 de abril de 2002, que dispõe sobre a Língua Brasileira de Sinais - Libras. Brasília, 2005. p. 01-05.

BRASIL, Lei n $^{\circ}$ 9.394/96 de 20 de dezembro de 1996. Estabelece as diretrizes e bases da 
educação nacional, Brasília, 1996.

BRASIL. Lei n. ${ }^{\circ}$ 10.436, de 24 de abril de 2002. Dispõe sobre a Língua Brasileira de Sinais Libras - e dá outras providências. Brasília, 2002. p. 01.

BRASIL. Ministério da Educação. Política nacional de educação especial na perspectiva da educação inclusiva. Brasília: MEC/SEESP, junho de 2008.

BRASIL. Ministério da Educação. Saberes e práticas da inclusão. Secretaria de Educação Especial. Brasília, 2006.

BRASIL. Ministério da Educação. Ensino de língua portuguesa para surdos: caminhos para à prática pedagógica. Vol. 1. Secretaria de Educação Especial. Brasília, 2004.

CHOMSKY, N. Novas perspectivas linguísticas. Petrópolis: Vozes, 1971.

FERNANDES, E. Língua de sinais e desenvolvimento cognitivo da criança surda. Espaço. Rio de Janeiro: INES, 2000.

LENT, Roberto. Cem Bilhões de Neurônios? Conceitos Fundamentais de Neurociência. $2^{\text {a }}$ ed. Rio de Janeiro.: Atheneu, 2010.

LOPES, Bruno Rege. SANTOS, Mônica Maria. Impasses da educação inclusiva: o luto simbólico do filho idealizado e o ensino da língua portuguesa para alunos surdos. Barra do Garças. Revista Panorâmica - ISSN 2238-9210 - Edição Especial 202º p. 188-207. disponível

em:

http://revistas.cua.ufmt.br/revista/index.php/revistapanoramica/issue/view/50/showToc.

Acessado em: 25/05/2020.

MORATO, E.M. Da relação entre linguagem e congnição. In.: RESENDE, B.D.; LIMAHERNANDES, M.C.; DE PAULA, F.V.; MÓDOLO, M.; CAETANO, S.C. Polifonia, Cuiabá-MT, v. 25, n.38.1, p. 193-388, maio-agosto.2018. 302 (orgs.). Linguagem e cognição: um diálogo interdisciplinar. Lecce / Rovato - Itália: Pensa MultiMedia Editore s.r.l., 2015, p. 25-51.

PERLIN, G. T. T.. 'Identidades surdas'. In SKLIAR, C. (org.) A surdez: um olhar sobre as diferenças. Porto Alegre, Mediação, 1998.

SILVA; A.B.P.\& COL. Surdez e Modalidade de Linguagem. Psic.: Teor. e Pesq., Brasília, Jul-Set 2007, Vol. 23 n. 3, pp. 279-286.

SOUZA, Celina. Políticas públicas: uma revisão da literatura. Sociologias $n^{\circ} .16$ Porto Alegre July/Dec. 2006. Disponível em: https://www.scielo.br/scielo.php?pid=S1517-

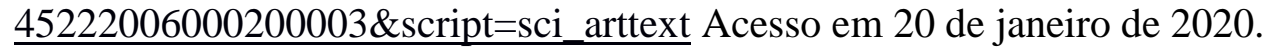




\section{REVISTA DE ADMINISTRAÇÃO EDUCACIONAL}

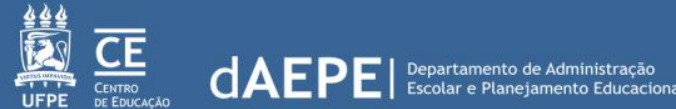

ISSN 2359-82

THOMA, A.; KLEIN, M. Experiências educacionais, movimentos e lutas surdas como condições de possibilidade para uma educação de surdos no Brasil. Cadernos de Educação | FaE/PPGE/UFPel | Pelotas [36]: 107 - 131, maio/agosto. 2010.

ZAVAREZE, T.E. A construção histórico cultural da deficiência e as dificuldades atuais na promoção da inclusão. O portal dos Psicólogos. Florianópolis, 2009. Disponível em: https://www.psicologia.pt/artigos/textos/A0478.pdf. Acesso em: 30 jan. 2020.

UNESCO, a Conferência Mundial sobre Necessidades Educacionais Especiais, Salamanca, 1994.

UNESCO, Declaração Mundial sobre Educação para Todos: satisfação das necessidades básicas de aprendizagem. Jomtien, 1990.

WRIGLEY, O. The politics of deafness. Washington. Gallaudet University Press, 1996. 